On Magnetic Oscillators as Radiators in Wireless Telegraphy

This content has been downloaded from IOPscience. Please scroll down to see the full text. 1907 Proc. Phys. Soc. London 2147

(http://iopscience.iop.org/1478-7814/21/1/304)

View the table of contents for this issue, or go to the journal homepage for more

Download details:

IP Address: 131.91.169.193

This content was downloaded on 01/10/2015 at 10:33

Please note that terms and conditions apply. 


\section{On Magnetic Oscillators as Radiators in Wireless}

Telegraphy. By J. A. Flaming, D.Sc., F.R.S.*

AN oscillator of the open or Hertzian type is commonly called an electric oscillator because the effects produced in the external field are to a large extent determined by the potential of the free electric charges which alternately make their appearance on the open ends. If, however, the oscillator consists of a metallic circuit completed by a condenser, the plates of which are very near together, the effects in the external space are mostly or entirely determined by the current in the circuit and little if at all by the condenser-plate charges, because these being of opposite sign end near together neutralize each other's effects in the field. Such a closed or nearly closed circuit is called a magnetic oscillator. In the case of an open oscillator or simple doublet Hertz showed that if $\phi$ is the maximum electric moment, or product of the maximum static charge on eacb end and the distance between them, and if $\lambda$ is the wave-length of the emitted radiation, the energy radiated by the oscillations in ergs per period is given by the expression

$$
\mathrm{E}=\frac{16 \pi^{4} \phi^{2}}{3 \lambda^{3}} \text {. . . . . . . }
$$

This expression can be reduced to a more convenient form for practical measurement as follows :-

Let $\mathrm{C}$ be the capacity in microfarads of each sphere or half of the oscillator with respect to the other, and $V$ be their maximum potential difference in volts before discharge, then $9 \times 10^{5} \mathrm{CV} / 300=3000 \mathrm{C} \mathrm{V}$ is the maximum value of the charge in electrostatic units.

Hence if $l$ is the length of the oscillator in cms., we have for the electric moment,

$$
\phi=3000 \text { C.V.l. . . . . . . }
$$

Let the current at the centre of the oscillator have a maximum value $A$ reckoned in amperes, and let $a$ be the

* Read October 25, 1907. 
root-mean-square or effective value in amperes as measured by a hot-wire ammeter.

Then, if the oscillations are sinoidal in form, undamped or persistent, and of frequency $\mathrm{N}$, we have

$$
\begin{aligned}
& \mathrm{A}=2 \pi \mathrm{N} \mathrm{C} \mathrm{V} / 10^{6}, \text {. . . . . } \\
& a=\frac{\mathrm{A}}{\sqrt{2}} \text {. . . . . . . . . }
\end{aligned}
$$

Hence the energy $E$ radiated per period in ergs is given by

$$
\mathrm{E}=4 \pi^{2} 10^{8} \frac{l^{2}}{\lambda^{2}} \frac{\mathrm{A}^{2}}{\mathrm{~N}}, \quad . \quad . \quad . \quad .
$$

and the power $W$ in watts by

$$
\mathrm{W}=40 \pi^{2} \frac{l^{2}}{\lambda^{2}} \mathrm{~A}^{2} \text {. . . . . . . }
$$

Remembering that $\pi^{2}=9.87$ and $N \lambda=3 \times 10^{10}$, we can write the above formulæ in the convenient form

$$
\begin{aligned}
& \mathrm{E}=0.2632 \frac{l^{2}}{\lambda} a^{2}, \quad . \quad . \quad . \quad . \quad . \\
& \mathrm{W}=789 \cdot 6 \frac{l^{2}}{\lambda^{2}} a^{2} \cdot \cdot \cdot \cdot \cdot \cdot \cdot \cdot
\end{aligned}
$$

The value of the ratio $l / \lambda$ can be determined experimentally for any oscillator. For a simple linear oscillation it approximates in value to 0.4 . Hence for such an oscillator radiating undamped waves, the power radiated in watts is given by the expression $\mathrm{W}=126 a^{2}$. Thus, for instance, if the effective value of the current at the centre of the oscillator is 2 amperes, the radiation will be half a kilowatt. If we then consider the case of a perfectly closed oscillation circuit having an aren $S$ and traversed by undamped or persistent oscillations which have a maximum value $A$ and R.M.S. value $a$ reckoned in amperes, it can be shown that such a closed circuit also radiates energy, and we can derive a similar formula for the radiation to that given by Hertz for the open circuit. The author has shown that if $M$ is the maximum magnetic moment of such a closed circuit*,

* See 'The Electrician,' vol. lix. p. 936 (1007). A series of arijcles on "The Elementary Theory of Electric Oscillators," by J. A. Fleming. 
viz., the product of its area $S$ and the maximum value of the alternating current (reckoned in electromagnet measure) in it; and if $\lambda$ is the wave-length of the radiation emitted by it, and $E$ the radiation in ergs per period, then for the magnetic oscillator we have

$$
\mathrm{E}=\frac{16 \pi^{4} \mathrm{M}^{2}}{3 \lambda^{3}} . \text {. . . . . }
$$

But by definition $\mathrm{M}=\mathrm{AS} / 10$, and if the current is sinoidal $a=\mathrm{A} / \sqrt{2}$, hence we have

$$
\mathrm{E}=10 \cdot 4 \frac{\mathrm{S}^{2} \alpha^{2}}{\lambda^{3}} \text {. . . . . . . }
$$

Furthermore, if the oscillations are persistent the power in watts $W$ radiated is given by

$$
\mathrm{W}=31,200 \frac{\mathrm{S}^{2} a^{2}}{\lambda^{4}} \cdot \text {. . . . }
$$

The formulæ (8) and (11) can be written in the form

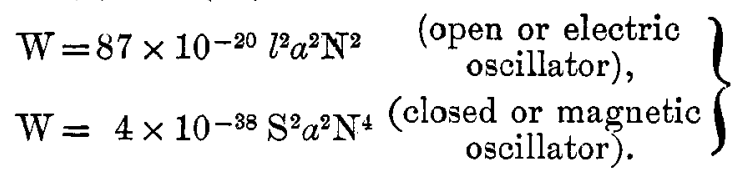

These last two formula show us that in the case of the open or electric oscillator the power radiated varies as the square of the current in it, and as the square of the frequency, whereas in the case of the closed or magnetic oscillator it varies as the square of the current but as the fourth power of the frequency. Accordingly, in the case of the magnetic oscillator the radiation is small unless the frequency is very high.

For the purposes of theory, it is most convenient to consider a closed oscillatory circuit as made up of a series of Hertzian or dumbbell oscillators placed in series with their electric poles of opposite sign overlapping. We can then easily determine the nature of the electric and magnetic field produced by it by the summation of those due to the elementary oscillators. As the writer has given lately in another place a discussion of the problem and furnished the expressions for the electric and magnetic forces at any point in the field of such a closed oscillator and the derivation of the formula (10) for the radiation, it is unnecessary to go 
over the ground again here. (See 'The Electrician,' vol. 59, p. 936 et seq.)

The object of the following experiments was to obtain some information as to the actual distance-effects of closed oscillators of certain dimensions, and to ascertain whether true radiation was at all influential in producing the inductive action of one closed oscillatory circuit on another at moderate distances, or if the whole of the action could be accounted for by ordinary electromagnetic or Faradaic induction.

The following circuits were employed for this purpose :-

Two pair of square circuits were constructed by winding a few turns of highly insulated copper wire round a wooden cross.

One pair had sides 8 feet in length, each frame carrying two coils of 5 turns of $7 / 21$ stranded insulated copper wire. These will be referred to as the "large square coils."

One pair had sides 2 feet in length, each frame carrying one coil of 8 turns of the same sized wire. These are referred to as the "small square coils."

The experiments consisted in setting up continuous or undamped oscillations in one of these coils by means of a Poulsen arc and then measuring the current create 1 in the corresponding coil placed at a dist ince by means of the Author's oscillation-valve or glow-lamp detector. The two coils were placed at various distances and in various respective positions. The coils themselves were erected or placed in the large quadrangle of University College, London. As the arc apparatus had to be placed indoors in the Electrical Laboratory it was necessary to connect the coil used as a transmitter or primary coil with the oscillation-producing apparatus by means of a long pair of insulated parallel copper (7/21) wires $14 \mathrm{cms}$. apart and $27 \frac{1}{2}$ feet or $836 \mathrm{cms}$. long.

The first step was to measure the inductance of these wires for high frequency currents. Anderson's bridge method was employed with a commutator as described by the Author.*

* See J. A. Fleming, "A Note on the Measurement of Small Inductances and Capacities," Phil. Mag. May 1904, p. 586.

See also J. A. Fleming" and W. C. Clinton, "On the Measurement of Small Capacities and Inductances," Phil. Mag. May 1903, p. 493. 
The inductance of the parallel wires or tails above mentioned was found to be $50,910 \mathrm{cms}$, and that of one large coil of 5 turns on the 8-foot square together with the tail (L) was $310,740 \mathrm{cms}$. Herre the inductance of the coil itself of 5 turns was $259,830 \mathrm{cms}$. The inductance of the two coils each of 5 turns in parallel was $198,350 \mathrm{cms}$., and in series $779,300 \mathrm{cms}$.

The inductance of each of the small or 2-foot square coils was in the same manner fourd to be $116,200 \mathrm{cms}$.

In series with these coils was placed a condenser having a capacity (C) of $0.0026 \mathrm{mfd}$. and the coil and condenser shunted across a 400-volt Poulsen arc.

The arc current was generally about 8 amperes, the potential difference of the arc terminals $\left(V_{0}\right) 260$ volts (continuous). The potential difference $\left(V_{1}\right)$ (R.M.S. value) of the condenser terminals was 1580 volts as measured by an electrostatic-voltmeter and the R.M.S. current $(a)$ in the square coil was 4.22 amperes as measured by a hot-wire ammeter. The frequency $\mathrm{N}$ of the oscillations is given by the formula $\mathrm{N}=\left(5.033 \times 10^{6}\right) / \sqrt{\mathrm{CL}}$. Hence if $\mathrm{C}=0.0026$ mfd. and $L=310740$ cms., we have $N=177,100$. If the R.M.S. current $(a)$ in the coils were strictly sinoidal in waveform, the value should be calculable from the formula,

$$
a=\frac{2 \pi}{10^{6}}(y \mathrm{VN}
$$

where $\mathrm{V}=\sqrt{ } \overline{\mathrm{V}}_{1}^{2} \overline{\mathrm{Z}} \mathrm{V}_{0}^{2}=\sqrt{(1580)^{2}-(260)^{2}}=1560$ volts. Hence we should have

$$
a=\frac{44}{7} \times \frac{26}{10^{10}} \times 1560 \times 177100=4.52 \text { amperes. }
$$

The actual measured value was 4.22 or $7 \cdot 3$ per cent. less, which may be accounted for by the known fact that the actual wave-form of the current in the coil is not by any means truly sinoidal.

The wave-length $\lambda$ corresponding to a frequency of 177100 is nearly $169,000 \mathrm{cms}$, , or rather more than 1 mile in length.

The total area $\mathbf{S}$ of the large coils using the 5-turn circuit is $5 \times(243 \cdot 2)^{2} \mathrm{cms}=295,731$ sq. cms, and the value 
of $\mathrm{S}^{2} a^{2}$ is therefore $(295731)^{2} \times(4 \cdot 22)^{2}=156 \times 10^{10}$. Also $(177100)^{3}=554523 \times 10^{10}$. For a closed square radiator the energy in ergs radiated per period is given as already mentioned by the expression

$$
\mathrm{E}=10 \cdot 4 \frac{\mathrm{S}^{2} a^{2}}{\lambda^{3}}
$$

Hence we have in this case for the power $W$ radiated in ergs per second,

$$
\mathrm{W}=\frac{10 \cdot 4 \times 156 \times 177000}{55 \pm 523}=522(\text { nearly })
$$

or about 52 microwatts.

This is the energy sent out per second through the surface of a sphere described round the oscillator the radius of which is large compared with the wave-length of the oscillator in question.

It is evident therefore that the true radiative power of a closed circuit of the above dimensions is extremely small compared with that of an open oscillator of the same order of linear dimensions.

Hence when a closed circuit traversed by a bigh frequency current acts to produce secondary currents in anotler similar circuit at less than a wave-length distance from it, the chief part of the effect cannot be due to true radiation or detached energy but is the result of ordinary electromagnetic induction, or the creation of secondary currents produced by the $\mathrm{ebb}$ and flow or pulsation of the lines of magnetic force permanently connected with the primary circuit*.

Nevertheless experiment shows that such circuits may act appreciably upon one another at very considerable distances, when the primary circuit of one is traversed by a high frequency current, and the circuits are in resonance with each other.

The old form of wireless telegraphy based upon such mutual induction between closed coils, as in the arrangement

* Moreover,just as in the case of the Hertzian oscillator true radiation or detachment of energy only takes place about $\frac{1}{4}$ or $\frac{1}{2}$ a wave-length from the oscillator, so in the case of the closed or magnetic ascillator true radiation effects can only be produced at a similar distance from it. 
suggested by Trowbridge and Stevenson, or the parallel wire method of Preece, Rathenau and others, employed relatively low frequency currents because the receiver used was the telephone, and the frequency was therefore limited by the range of audition. Even when the circuits were put in resonance, as by Lodge, the difficulties connected with the disturbance of commercial telephony restricted the possibilities of its use apart from other considerations.

One object of the present experiments was to obtain data for an opinion whetber such inductive wireless telegraphy could be improved by the use of electric oscillations of highfrequency in completely non-earthed circuits so that no disturbance of telephones or telegraphs could possibly arise combined with the use of a suitable oscillation detector. With this end in view, a closed primary-circuit bad created in it continuous or undamped electric oscillations, and its inductive and radiative effect upon a similar closed receiving. circuit was measured by means of the Oscillation Valve or Glow-Lamp Detector first described by the Author in 1904.

It consists of a 12-volt carbon filament glow-lamp with a metal cylinder surrounding the filament sealed into the bulb. The cylinder is carried on a platinum wire sealed through the glass. The filament is incandesced by a 6 -cell secondary battery. If the terminals of a condenser inserted in an oscillatory circuit are connected, one to the cylinder and one to the negative terminal of the lamp filament, and if an ordinary movable coil galvanometer is inserted in this circuit, then when oscillations occur in the condenser the glow-lamp acts as an electrical valve and the galvanometer is traversed by a continuous current which bears a definite relation to the potential difference of the condenser terminals and therefore to the current into it*.

* This glow-lamp detector or oscillation valve was first described by $m e$ in a British Patent Specitication, No. 24,850 of 1904, and in a Paper to the Royal Society (see Proc. Roy. Soc., vol. lxxiv. p. 476) in February 1905. Also in a United States Patent Specification, No. 803,684 of 1905, and in a Paper to the Physical Society of London (see Phil. Mag. May 1906), as well as in a book on the Principles of Electric Wave Telegraphy, pubished in May 1906. These publications apparently failed to make it known in the United States, for in October 1906 Dr. Lee de Forest described to the American Institute of Electrical 
To calibrate the valve the following arrangement was employed. An oscillatory circuit was arranged consisting of one of the small square coils $L$ (see fig. 1) and a condenser or Leyden jar $\mathrm{C}$ in series with it. In this circuit at one point was inserted a fine constantan wire having a thermo-junction (T) of iron and bismuth or bismuth and tellurium in contact with it. The arrangement actually employed was either the thermo-junction usad with the Author's Cymometers or else

Fig. 1.

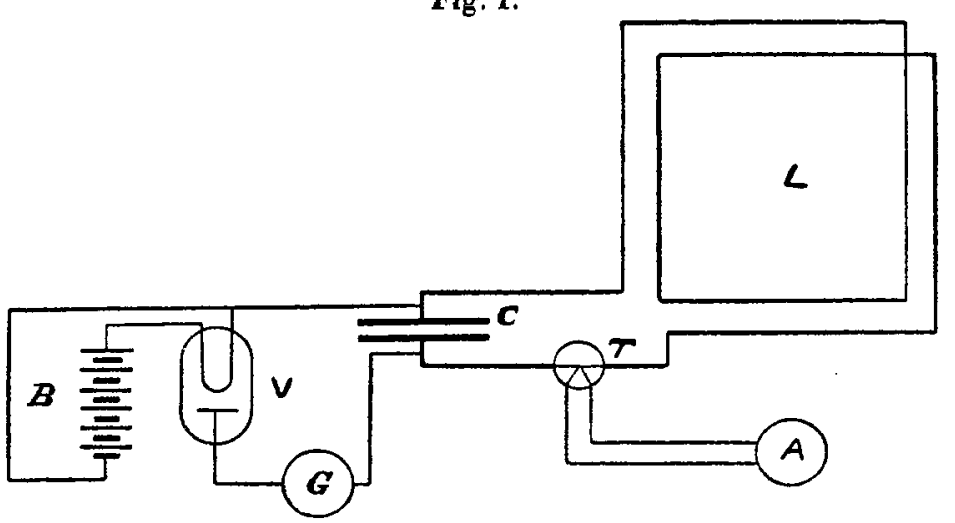

the thermoelectric receiver described some time ago* (see fig. 1).

The galvanometer A associated with the junction was a 5-ohm single-pivot Paul galvanometer. The arrangement, was calibrated by first passing measured continuous currents through the constantan wire and observing the corresponding scale-readings of the Paul galvanometer. The curve plotted out proved to be very approximately a parabola, the galvanometer deflexion being very nearly proportional

Engineers precisely the same device, viz., a carbon flament glow-lamp having a plate sealed into the bulb as a detector for electric oscillations, as his own invention and re-christened this two-year old appliance an audion. No re-christening, however, affects the fact that the appliance had been in use by me long previously and especially described as a recejver for wireless telegraphy.

* See "Radiation from Bent Antennæ," by J. A. Fleming, Phil. Mrag. December 1906, p. 592. 
to the square of the heating current sent through the constantan wire. When electric oscillations were set up in the circuit they heated the constantan wire and caused a deflexion of the Paul galvanometer from which by the previous calibration their mean-squre value could be determined. In addition the oscillation valve $V$ joined in as shown in fig. 1 passed a continuous current through the galvanometer $G$ in its eircuit, and readings were taken of this current in microamperes corresponding to various measured valnes of the oscillatory current in the square circuit which passed through the constantan wire.

The object of this calibration was to be able to use the valve subsequently as a means of measuring the oscillatory

Fig. 2.

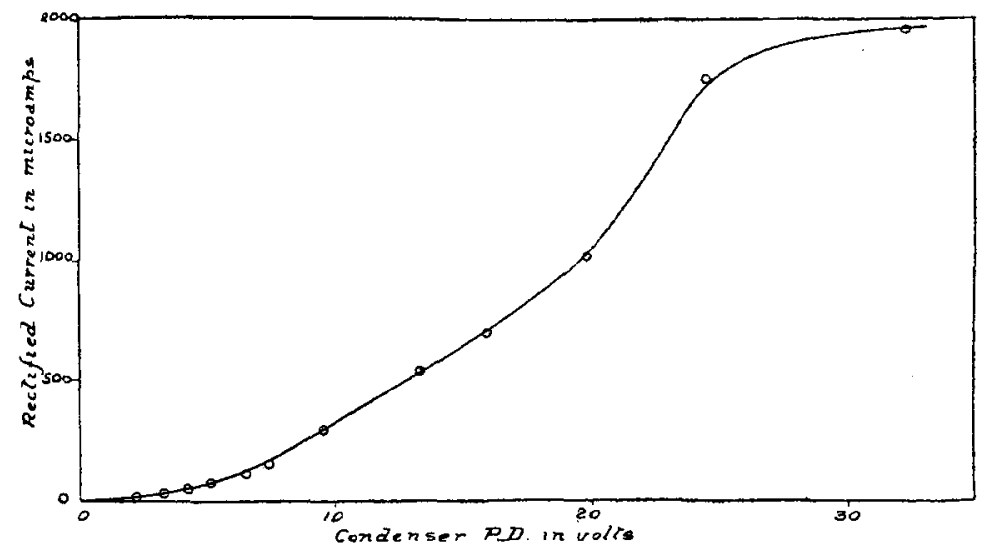

current induced in the circuit when it had a value less than that which could be easily measured by the thermojunction, for when associated with a suitable mirror-galvanometer it provides the means of measuring a bigh frequency current of a few microamperes. Moreover it does not introduce any extra resistance into the circuit, as would have been the case if the constantan wire and themojunction had been permanently inserted into the circuit. Observations showed that the galvanometer current did not increase proportionately to the condenser plate potential difference, but tended to a "saturation" value as shown by the curve in fig. 2. 
The large (8-feet) square coils were then set up in the quadrangle of University College, one being used as a transmitter and the other as a receiver circuit.

The transmitter coil, in series with a suitable condenser, was connected by the long parallel wires or tails with a Poulsen are in the adjacent electrical laboratory, and persistent oscillations excited in it. The similar receiver circuit at a distance had a condenser of equal capacity in series with it and a variable inductance for tuning. The oscillation valve had its terminals connected to the receiver circuit condenserplates and wires taken from it to a mirror galvanometer placed in a distant room. The transmitter coil bad then persistent oscillations set up in it by the arc, and the transmitter and receiver coils were placed at various distances and in various relative positions, and the current created in the received circuit was in each case measured by the galvanometer and valve.

When either of the square coils were placed with their planes normal to the line joining their centres and vertical to the earth surface, we shall call this position $A$. When either of them were placed with plane parallel to the line joining their centres and vertical to the earth we shall call the position $B$, and when they were placed with plane parallel to the surface of the earth we shall call this position $C$. Thus if we represent the coils as seen in plan or looking down on them from above we can denote these positions as follows: -

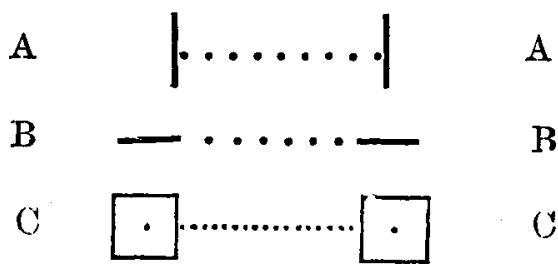

The dotted lines represent the line joining their centres. The following experiments were then made :-

ExP. I. Eiffect of varying the position of the coils.-The two 8 -feet coils of 5 turns each were set up with centres 60 feet apart. The transmitter current was 5.4 amperes. The 
capacity in the transmitter circuit $0.0026 \mathrm{mfd}$. The receiver was tuned to a frequency of 164,000 in syntony with the transmitter and undamped oscillations were set up in the latter by the arc. The electric arc was adjusted to keep a constant high-frequency current in the transmitter circuit of $5 \cdot 4$ amperes. The arc current itself was 8 amperes and arc P.D. from 260 to 320 volts.

The transmitter was put successively in positions A, B, and $\mathrm{C}$, and in each case associated with receiver in positions $\mathrm{A}$, $B$, and $C$, and the receiver or secondary current in milliamperes being measured. The results are tabulated in Tuble I.

TABLE I.

\begin{tabular}{|c|c|c|}
\hline $\begin{array}{c}\text { Transmitter } \\
\text { Position. }\end{array}$ & $\begin{array}{c}\text { Receiver } \\
\text { Position. }\end{array}$ & $\begin{array}{c}\text { Secondary Current } \\
\text { in milliamperes. }\end{array}$ \\
\hline A & A & $24 \cdot 16$ \\
B & $10 \cdot 77$ \\
$"$ & C & $20 \cdot 98$ \\
B & A & $5 \cdot 25$ \\
$"$ & B & $20 \cdot 45$ \\
O & C & $18 \cdot 10$ \\
$"$ & A & $6 \cdot 56$ \\
$"$ & B & $22 \cdot 58$ \\
\hline
\end{tabular}

When the coils were in position $C$ their planes were 6 inches above the ground.

The figures in Table I. show that when both coils were in position $C$ the receiver current exceeded that in any other position, and that although the receiver current was small with the coils in the positions of zero mutual induction, viz. (A.B.), (B.A.), or (C.A.), it was not small in the position (A.C.).

In the case of two small coils placed at a distance large compared with their dimensions the magnetic induction for a steady field should by theory be twice as great in the position (A.A.) as in the position (B.B.), and should be the 
same in position (C.C.) as in position (B.B). Also zero in the 6 positions (A.B.), (B.A.), (C.B.), (B.C.), (A.C.), (C.A.).

But when using the high-frequency primary current the secondary current is still large in the cases (A.C.),( B.C.), and (C.B.), viz., when either the receiver or transmitter coil has its plane parallel to the earth's surface.

Subsequent results showed that the height of the coils above the ground affected this result considerably. Nevertheless the exalted effect in position (C.C.) is interesting and convenient because it is easy to construct large circuits out of doors in positions (C.C.) and very much less easy without the aid of tall masts to make them in the positions (A.A.) or (B.B.).

Exp. II. Effect of varying distance. Coils vertical.-The same pair of coils were set up on positions (A.A.) and their distances varied. The receiver circuit was tuned to a frequency of 162,000 , and the primary current was $4 \cdot 7$ and $5 \cdot 4$ amperes in two sets of observations respectively.

TABLE II.-(oils in position (A.A.).

\begin{tabular}{|c|c|c|}
\hline $\begin{array}{c}\text { Distance of Centres } \\
\text { in feet. }\end{array}$ & $\begin{array}{c}\text { Primary Current } \\
\text { in amperes. }\end{array}$ & $\begin{array}{c}\text { Secondary Current } \\
\text { in nilliamperes. }\end{array}$ \\
\hline 78.0 & 5.4 & 13.7 \\
123.5 &, & 6.46 \\
170.5 & $"$, & $1 \cdot 17$ \\
237.0 & $"$ & 0.12 \\
36.2 & 4.7 & 41.9 \\
88.0 & $"$, & 6.99 \\
123.2 & $"$ & 3.05 \\
169.7 & $"$ & 1.01 \\
237.0 & $"$ & 0.11 \\
\hline
\end{tabular}

The results are plotted in the curve in fig. 3.

The curve shows that the inductive effect decreases at first very rapidly with the distance, less rapidly than the 
inverse cube but rather more than the inverse square of the distance.

Fig. 3.

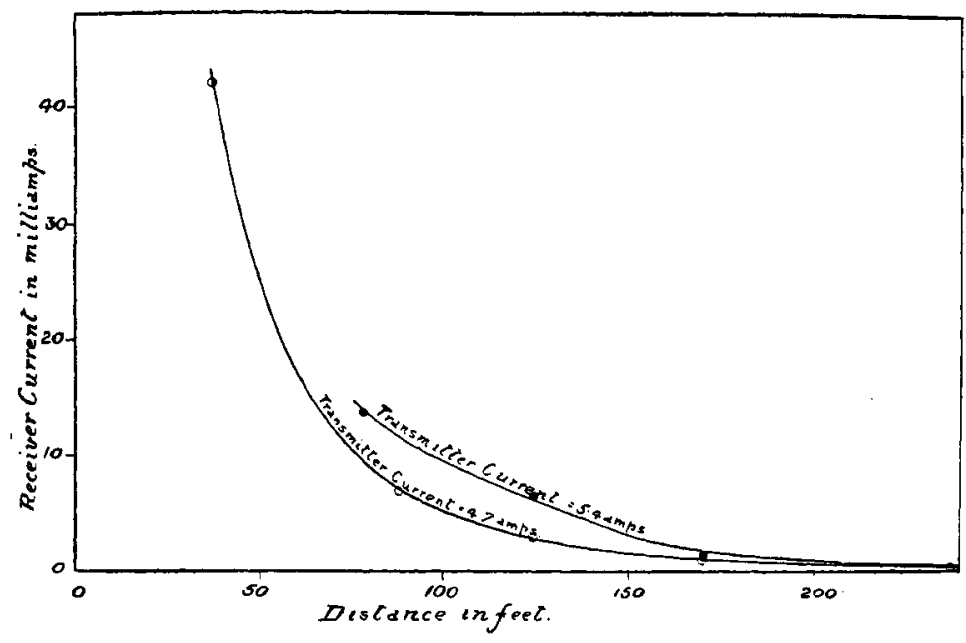

Exp. III. Effect of varying distance. Coils horizontal.The same coils were set in positions (C.C.) with centres 6 inches above the ground. The receiver circuit was tuned to a frequency of 162,000 , and the primary current was $5 \cdot 4$ amperes.

TABLE III.-Coils in position (C..C.).

\begin{tabular}{|c|c|c|}
\hline $\begin{array}{c}\text { Distance of Centres } \\
\text { in feet. }\end{array}$ & $\begin{array}{c}\text { Primary Ourrent } \\
\text { in auperes. }\end{array}$ & $\begin{array}{c}\text { Secondary Current } \\
\text { in nilliawperes. }\end{array}$ \\
\hline 33 & 5.4 & 53.1 \\
68 & $n$ & 41.4 \\
121 & $n$ & 12.4 \\
175 & $n$ & 0.57 \\
236 & $"$ & 0.28 \\
\hline
\end{tabular}

Here again the current falls off at a rate between the inverse cube and inverse square, but the secondary current has a much greater absolute value for the same distance than 
with the coils in positions (A.A.). The results are set out in the curve in fig. 4.

Fig. 4.

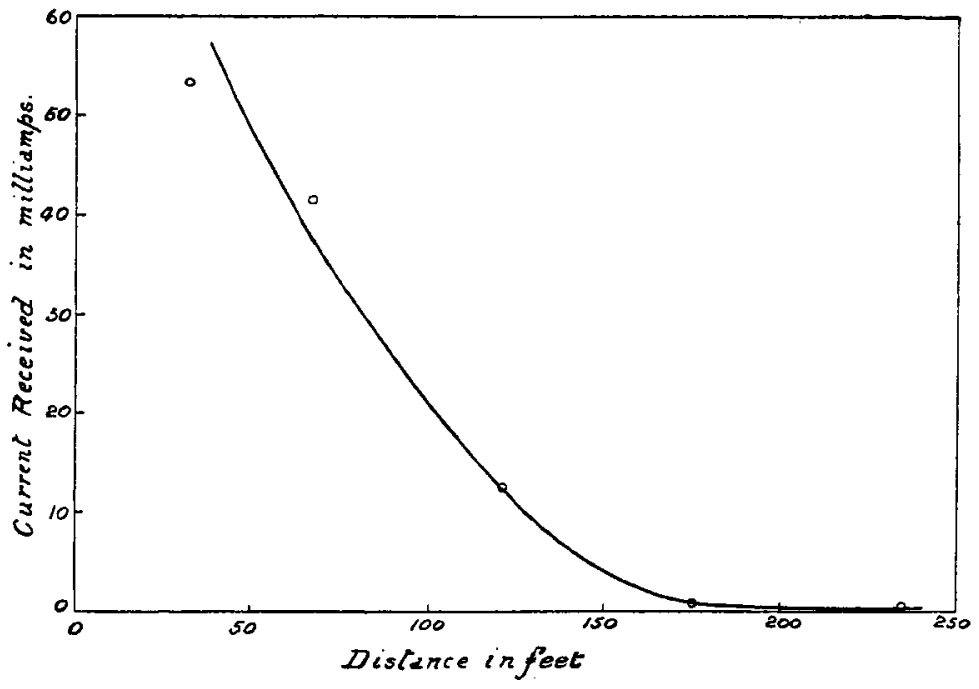

Exp. IV. Effect of varying distance. Small coils horizontal aud 6 inches above the ground.-A similar set of measurements were made with the small coils 2 feet in side and having 8 turns on each coil. The primary current was $5 \cdot 4$ amperes. The receiver circuit was tuned to a frequency of 214,400 in syntony with the transmitter current.

The coils were placed at various distances and the receiver currents measured.

TABLE IV.

\begin{tabular}{|c|c|c|}
\hline $\begin{array}{c}\text { Distance of Centres } \\
\text { in feet. }\end{array}$ & $\begin{array}{c}\text { Primary Current } \\
\text { in amperes. }\end{array}$ & $\begin{array}{c}\text { Secondinry Currerit } \\
\text { in milliamperes. }\end{array}$ \\
\hline 20 & 5.4 & 2.045 \\
35 & $n$ & 0.402 \\
55 & $n$ & 0223 \\
80 & $n$ & 0.045 \\
105 & $n$ & 0.027 \\
130 & $n$ & 0.034 \\
\hline
\end{tabular}


The same law of variation holds good in this case also as shown by the curve in fig. 5 .

Fig. 5.

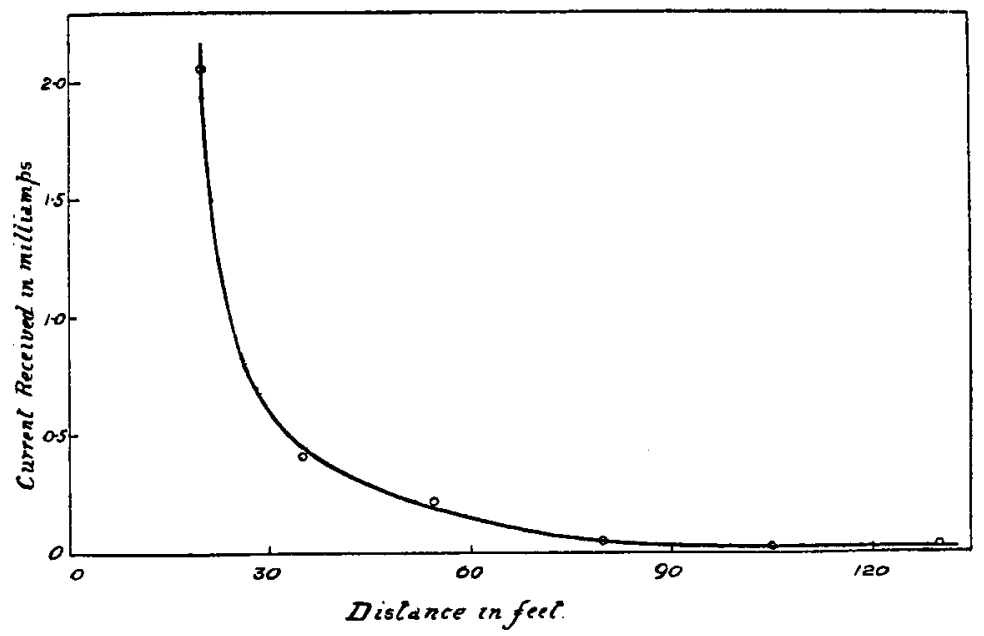

Exp. V. Effect of varying height above the ground. Coils in position (A.A.) vertical.-The large coils were employed and raised step by step to various heights above the ground. The primary current was 5.4 amperes. The receiver was tuned to a frequency of 162,000 . The distance of the coils was 68 feet. The coils had their planes vertical and parallel to each other except in the last case when they were placed horizontal or in positions (C.C.) for comparison.

TABLE $\mathrm{V}$.

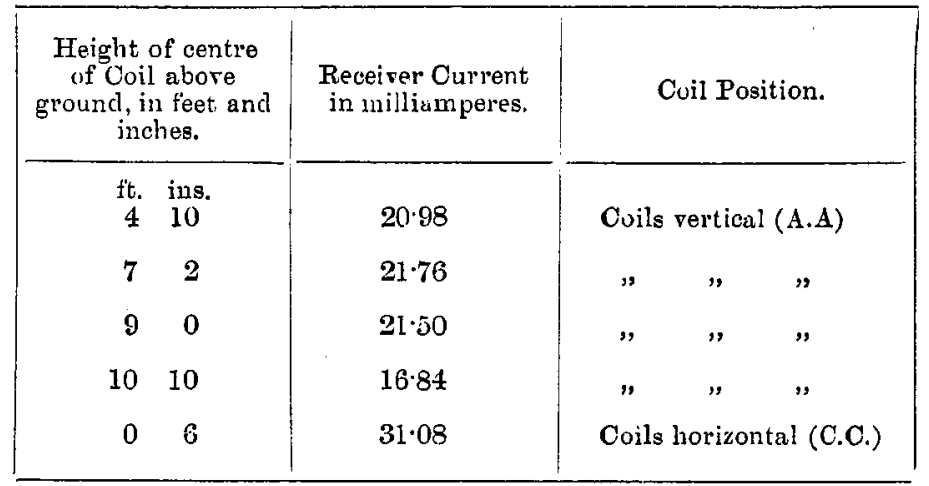

Here again is shown the improved effect of placing the 
coils with their planes parallel to the earth's surface. These observations are plotted in the curve shown in fig. 6 .

Fig. 6.

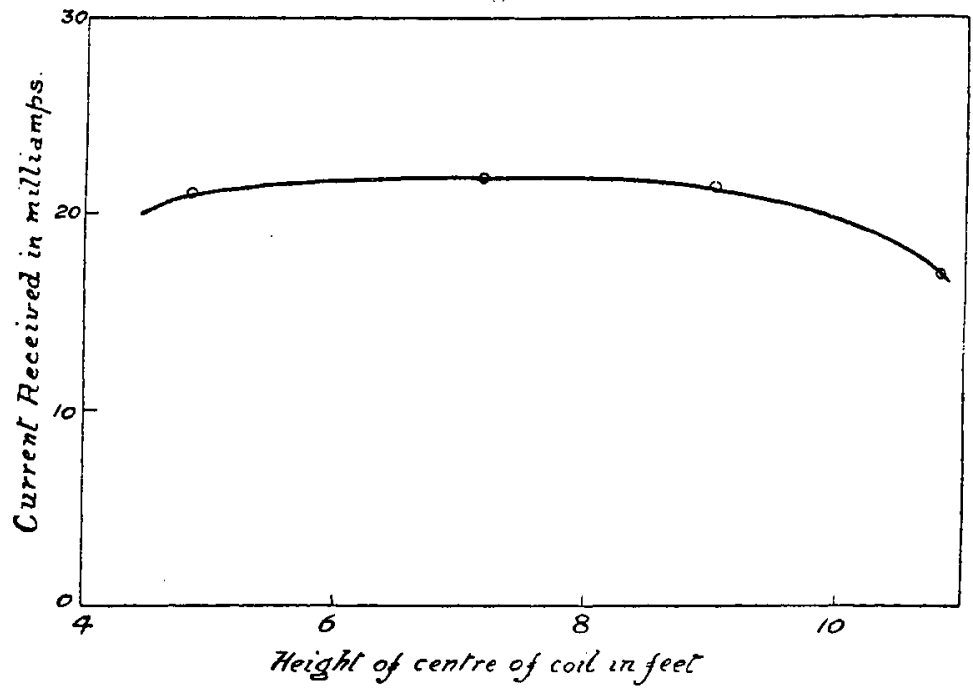

Exp. VI. The same measurement was made with the small coils 2 feet square of 8 turns, placed at a distance of 60 feet. The primary current was kept at $5 \cdot 4$ amperes. The receiver was tuned to a frequency of 214,000 and the secondary current was measured for various heights of the coils above the ground, the coils being vertical and in positions (A.A.).

TABLE VI.

\begin{tabular}{|c|c|}
\hline $\begin{array}{l}\text { Height of centre of } \\
\text { Coil above the ground, } \\
\text { in feet and inches. }\end{array}$ & $\begin{array}{c}\text { Secondary Current ln } \\
\text { milliamperes. }\end{array}$ \\
\hline $\begin{array}{cc}\text { ft. } & \text { ins. } \\
1 & 0\end{array}$ & $0 \cdot 160$ \\
\hline 14 & 0.460 \\
\hline 18 & 0.452 \\
\hline 23 & 0.515 \\
\hline 32 & 0.570 \\
\hline $5 \quad 3$ & 0327 \\
\hline 72 & 0.176 \\
\hline
\end{tabular}


The results of the last two experiments is to show that for constant primary current the receiver current is a maximum for a certain height of the coils above the earth's surface. The observations are delineated in fig. 7 .

Fig. 7.

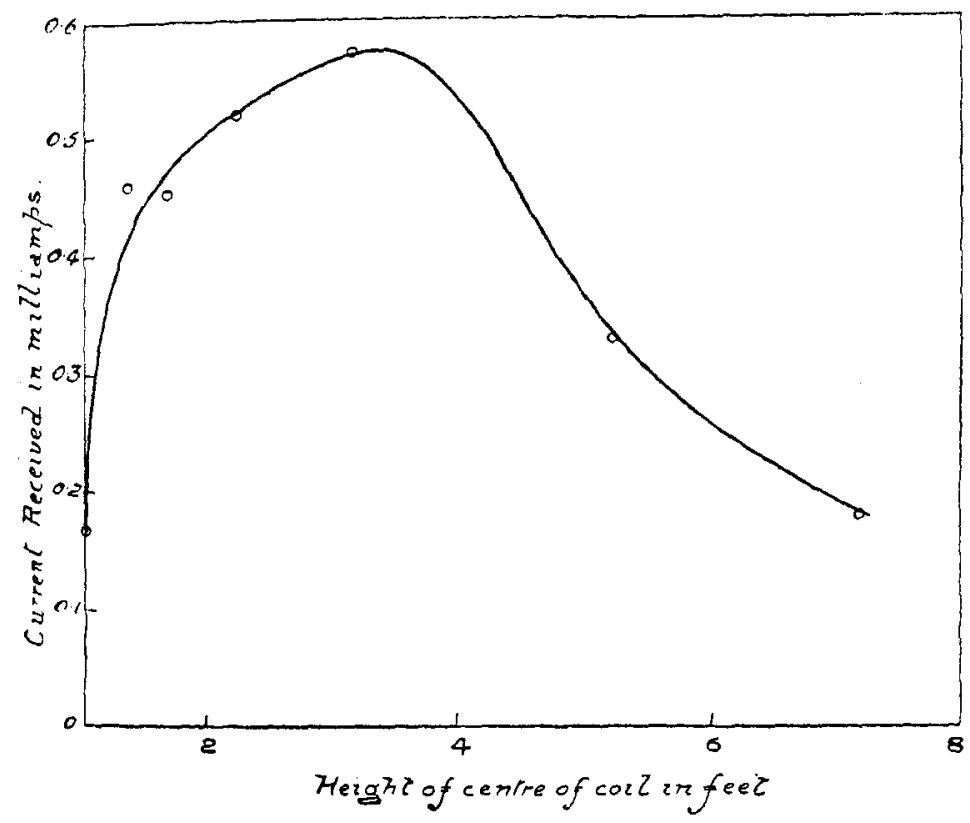

It is obvious, however, that all the measurements in which the cuils are placed horizontal and at varying heights above the ground need caution in inter preting them. When the coil is placed with its plane parallel to the earth, currents must he induced in the soil, and the effective inductance of the ccil and therefore the frequency of the current must be altered. The nearer the grom the less is the effective inductance of the coil, but on the other hand the capacity is increased. Hence, even if the primary high-pressure current is kept constant, there will he variations of frequency which affect the inductive action of the primary on the secondary. That such is the case was shown by the results of a further set of measurements with the large coils, the power taken up in the arc and its power-factor being observed at the same time. 
ExP. VII.-Large square coils placed parallel to the earth. Distance 68 feet. Receiver tunad to a frequency of 162,000 approximately in syntony with the transmitter. The coils were raised to various heights above the ground and the secondory current measured. The transmitter current was kept constant at $5 \cdot 4$ amperes.

TAJBLE VII.

\begin{tabular}{|c|c|c|c|}
\hline $\begin{array}{l}\text { Height of Coils } \\
\text { above the ground, } \\
\text { in feet and } \\
\text { inches. }\end{array}$ & $\begin{array}{l}\text { Power taken } \\
\text { up in Al'c } \\
\text { in watts. }\end{array}$ & $\begin{array}{l}\text { Power factor } \\
\text { of Arc. }\end{array}$ & $\begin{array}{l}\text { Secondary } \\
\text { Ourrent in } \\
\text { milliamperes. }\end{array}$ \\
\hline $\begin{array}{l}\text { ft. ins } \\
\text { On ground }\end{array}$ & 2328 & $1 \cdot 0$ & $45 \cdot 8$ \\
\hline $\begin{array}{ll}0 & 2\end{array}$ & $14: 24$ & 001 & $47 \cdot 4$ \\
\hline $\begin{array}{ll}0 & 6\end{array}$ & 1003 & 0.86 & $41 \cdot 2$ \\
\hline 11 & 1104 & 0.89 & $27 \cdot 7$ \\
\hline 17 & 1248 & 0.92 & $22 \cdot 5$ \\
\hline $2 \quad 2$ & 1272 & 0.93 & $16 \cdot 0$ \\
\hline 40 & $16 \pm 0$ & 1.00 & $5 \cdot 18$ \\
\hline 60 & 1856 & 0.98 & $8 \cdot 03$ \\
\hline
\end{tabular}

The above observations are reduced to graphic form in fig. 8 .

Fig. 8.

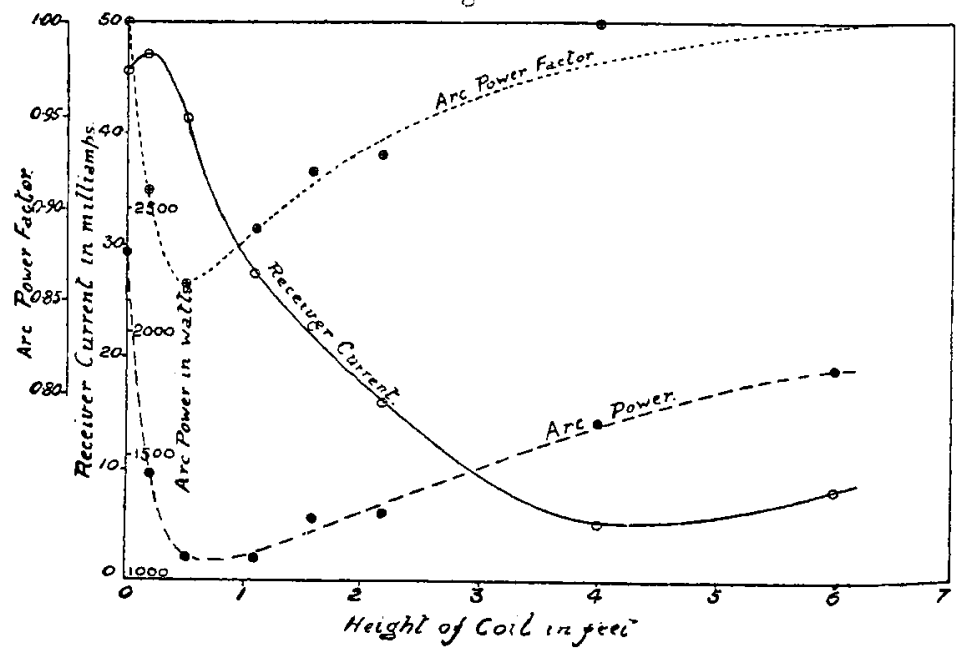


They show how much the receiver current varies with the height of the coils above the ground, the maximum value being reached when the coils are about 2 inches above the surface. Also they show that when the coils are laid flat on the ground there is a great increase in the power taken up by the arc.

Raising the coils from 6 inches to 6 feet above the ground decreased the secondary currents to one-fifth.

Exr. VIII. Comparison of coils of different areas.-The two large or 8-feet coils were compared with the two small or 2-feet coils. In both cases the distance between primary and secondary was 79 feet, and the coils were parallel to the earth and at 6 inches above the surface. In both cases the primary current was 5.4 amperes.

The small coils had 8 turns and were tuned to a frequency of 214,400 .

The large coils had $\mathbf{5}$ turns and were tuned to a frequency of 162,000 .

TABLE VIII.

\begin{tabular}{|c|c|c|c|}
\hline Coils used. & $\begin{array}{c}\text { Number } \\
\text { of turzs. }\end{array}$ & Frequency. & $\begin{array}{c}\text { Secondary } \\
\text { Culrent in } \\
\text { williamperes. }\end{array}$ \\
\hline $\begin{array}{c}\text { Small. } \\
2 \text { feet in side... }\end{array}$ & 8 & 214,400 & 0.082 \\
$\begin{array}{c}\text { Ln rge. } \\
8 \text { feet in side... }\end{array}$ & 5 & 162,000 & $27 \cdot 4$ \\
\hline
\end{tabular}

The large coil therefore produces $3 \pm 0$ times the effect of the small coil.

Exp. IX. Comparison of the same coils with different numbers of tums.-The two large coils were wound with two circuits each of 5 turns and they could be joined in series so as to make a coil of 10 turns. The coils were placed parallel to the earth and at a distance of 6 inches above it. The primary current used in both cases was 5.4 amperes. The inductance of the primary circuit was $380,000 \mathrm{cms}$., and when 10 turns were used it was $1,000,000 \mathrm{cms}$. The power

VOL. XXI. 
taken up in the arc therefore was not the same in the two cases.

TABLE IX.

\begin{tabular}{|c|c|c|c|}
\hline $\begin{array}{c}\text { Number } \\
\text { of turns } \\
\text { on Ooil. }\end{array}$ & $\begin{array}{c}\text { Power taken } \\
\text { up in Arc } \\
\text { in watts. }\end{array}$ & $\begin{array}{c}\text { Frequency } \\
\text { of } \\
\text { Oscillations. }\end{array}$ & $\begin{array}{c}\text { Secondary } \\
\text { Current in } \\
\text { milliamperes. }\end{array}$ \\
\hline 5 & 2495 & 162,000 & $27 \cdot 4$ \\
10 & 1537 & 99,600 & $21 \cdot 4$ \\
\hline
\end{tabular}

The increase in the number of turns by increasing the inductance lowers the frequency of the oscillations, and this lowers the power taken up in the arc, and therefore the secondary current is reduced roughly in proportion to the decrease in frequency. In all the above experiments the Poulsen are was used as a generator of undamped oscillations. It was considered desirable, however, to compare the effects obtained in this case with those when using a spark method of exciting intermittent oscillations.

The large square coils were placed vertical and facing each other in positions (A.A.) and at 68 feet apart. They were tuned to a frequency of 162,000 . Oscillations were then excited by an are and a spark and the primary and secondary currents measured and volt amperes given to the generator in each case, as follows :-

TABLE X.

\begin{tabular}{|c|c|c|c|c|c|}
\hline Generator. & Volts. & Amperes. & $\begin{array}{c}\text { Volt } \\
\text { amperes. }\end{array}$ & $\begin{array}{c}\text { Primary } \\
\text { Current in } \\
\text { aumperes. }\end{array}$ & $\begin{array}{c}\text { Secondary } \\
\text { Current in } \\
\text { milliamperes. }\end{array}$ \\
\hline Spark ......... & $12 \cdot 2$ & $2 \cdot 6$ & $31 \cdot 7$ & $2 \cdot 15$ & 0.56 \\
Arc ......... & 260 & $8 \cdot 0$ & 2080 & $5 \cdot 4$ & 21.0 \\
\hline
\end{tabular}

Roughly speaking, therefore, 70 times more power was being expended on the arc than on the induction-coil used to create the spark, but the secondiry current only increased some 38 times. 
This seems to indicate that the intermittent spark method of exciting the oscillations is not inferior but rather superior in efficiency to the are method, for the particular purpose here considered.

The conclusions to be drawn from this preliminary set of experiments are that the inductive effects observed between the closed oscillatory circuits used are in the main due to electromagnetic induction and not to true radiation. Secondly, that the most advantageous position of the coils is with the plane of the coils parallel to the earth's surface and at a small distance above it. Thirdly, that the increase in the area of the coils is especially advantageous, and that therefore the coils used should consist of single turns of wire enclosing as large an area as possible. Fourthly, that the inductance and capacity of the circuit must be kept low to keep up the frequency. Lastly, the spark method of exciting the oscillations can be advantageously employed.

The best method, therefore, for constructing and using such closed circuit antennæ for high-frequency closed circuit wireless telegraphy which seems to be indicated by the foregoing experiments is as follows :-

In some large field set up a number of short wooden posts having telegraphic insulators attached to them. Round these lay a number of wires, which may be bare copper wires, so as to form a closed circuit of one turn of a number of parallel wires, the circuit being say a foot or two from the ground, or if cows, horses, or sheep are kept in the field it may be better to keep it up 7 or 8 feet from the ground. Complete this circuit by a condenser and spark-gap and make provision by a high-tension transformer for exciting oscillations in the circuit.

In a similar distant and syntonised circuit include any of the receiving devices now employed in radio-telegraphy, and signals can be transmitted and received without high antenno and without interruption to commercial telephonic circuits. Such closed horizontal receiving circuits will not pick up signals from the vertical antenna transmitters commonly used.

The method suggested is in fact the old form of magnetic induction spaco-telegraphy, but conducted with electric 
oscillations in place of the low-frequency currents obtained by an ordinary alternator or interrupted battery-current. On the other hand, direct experiment with low-frequency alternating currents of 5.4 amperes passed through the small coils used in these experiments, showed that no inductive effects detectable at more than a few yards at most were apparent when using an ordinary telephone as a receiver. Even if the whole of the inductive effect is due to simple electromagnetic induction, the use of high-frequency currents is a distinct advantage.

The experiments bere described are merely a preliminary to large scale experiments in actual closed circuit telegraphy the writer hopes to be able to try later on.

One drawback to the magnetic induction form of telegraphy is the rapid rate at wbich the effect falls off with the distance. In the case of true radiation at long distances the forces vary inversely as the distance, but a more rapid rate of decay, something between the inverse cube and inverse square, holds good for the inductive effect at least at short distances. Hence the use of magnetic oscillators as transmitters is never likely for this reason alone to rival the electric or open oscillator, but there may be circumstances under which it is possible to use them with advantage. In conclusion the author desires to mention that the actual measurements recorded in this paper were taken by his assistant, Mr. G. B. Dyke, B.Sc., with the kind help of Mr. K. W. MeMillan, and to these gentlemen is due an acknowledgement of their share in the work, in making these observations with much intelligence and care.

\section{Discrssion.}

Mr. A. Russell thanked the anthn for his clear exposition of the theory of electric oscillators and for the valuable formula he gave for magnetic oscillators. The experiments described were exceediugly interesting and instructive. It was, however, difficult to interpret some of the results obtained. He asked whether the author had been able to find a position for the secondary coil in which no current was induced in it. Possibly buried pipes or metallic conducturs, iron girders in adjacent buildings or iron railings in the neighbourhood, might have had some influence in modifying the inductive effects between the coils.

Nr. TAYLon said that the Post Office had tried arrangements similar 
to those described for magnetic space telegraphy, and had found that the closed circuit method was inferior to that in which earth-connected vertical coils were used. The ratio between the received currents when using an earth-connected aud a closed circuit was often as great as eighty to one, and he thought the improvements in the closed-circuit method would have to be very great to make it equivalent to the earthed-circuit method.

V. On the Use of Tariahle Mritual Inductanres. By ALBERT CAMPBeli, B.A.* (From the National Physical Laboratory.)

[Plate IV.]

1. Introductory.

ConTENTS.

2. Mutual versus Self Inductance.

$3 \& 4$. Construction and Adjustment of Variable Mutual Inductances. $5,6,7 \& 8$. Uses of the same for measuring unknown Mutual Inductance, Self Inductance, and Capacity.

9. Appendix. The Scale of the Excentric-Coil Mutual Inductance.

\section{Introductory.}

THF accurate measurement of small self inductances and capacities has of late years assumed an increased importance owing to its direct practical application in connexion with wireless telegraphy; and much important and interesting work has been done on the subject especially as regards the calculation and measurement of self inductance. For some time past I have found that suitably designed mutual inductances are of the greatest assistance in such measurements, and I incline to think that by their use some of the sources of error inherent in other methods are avoided. The chief method (B) here described was designed for the measurement of the small self inductances (1 to 200 microhenries) used in wave telegraphy, and it has proved most useful in such work. Before I proceed to describe the designs and the methods of use which $I$ have found valuable, let us consider and compare mutual and self inductances in relation to their capabilities in practical use.

* Rerd October 25, 1907. 